Article

\title{
Sustainable Hues: Exploring the Molecular Palette of Biowaste Dyes through LC-MS Metabolomics
}

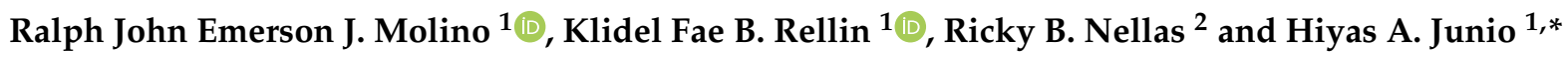 \\ 1 Secondary Metabolites Profiling Laboratory (SMPL), Institute of Chemistry, College of Science, \\ University of the Philippines, Diliman, Quezon City 1101, Philippines; rjmolino@up.edu.ph (R.J.E.J.M.); \\ kbrellin@up.edu.ph (K.F.B.R.) \\ 2 Virtual Biochemical Simulations Laboratory (Good VIBEs), Institute of Chemistry, College of Science, \\ University of the Philippines, Diliman, Quezon City 1101, Philippines; rbnellas@up.edu.ph \\ * Correspondence: hajunio@up.edu.ph
}

check for updates

Citation: Molino, R.J.E.J.; Rellin, K.F.B.; Nellas, R.B.; Junio, H.A. Sustainable Hues: Exploring the Molecular Palette of Biowaste Dyes through LC-MS Metabolomics. Molecules 2021, 26, 6645. https:// doi.org/10.3390/molecules26216645

Academic Editors: Eulogio

J. Llorent-Martínez and

Ruperto Bermejo-Román

Received: 13 October 2021

Accepted: 27 October 2021

Published: 2 November 2021

Publisher's Note: MDPI stays neutral with regard to jurisdictional claims in published maps and institutional affiliations.

Copyright: (c) 2021 by the authors. Licensee MDPI, Basel, Switzerland. This article is an open access article distributed under the terms and conditions of the Creative Commons Attribution (CC BY) license (https:/ / creativecommons.org/licenses/by/ $4.0 /)$.

\begin{abstract}
Underutilized biowaste materials are investigated for their potential as sustainable textile colorants through an approach based on mass spectrometry, bioinformatics, and chemometrics. In this study, colorful decoctions were prepared from the outer bark of Eucalyptus deglupta and fruit peels of Syzygium samarangense, Syzygium malaccense, Diospyros discolor, and Dillenia philippinensis. Textile dyeing was performed along with liquid chromatography-mass spectrometry (LC-MS)-based untargeted metabolomics to determine the small molecules responsible for the observed colors. Global Natural Products Social Molecular Networking (GNPS) guided the annotation of blackproducing proanthocyanidins in D. philippinensis and E. deglupta through complexation with $\mathrm{FeSO}_{4}$ mordant. Flavonoids from the yellow-colored D. philippinensis extracts were found to be similar to those in Terminalia catappa, a known traditional dye source. A higher intensity of epicatechin in E. deglupta produced a red-brown color in the presence of $\mathrm{Cu}^{2+}$. Furthermore, Syzygium fruit peels have poor wash-fastness in cotton fibers, but bioactive chalcone unique to $S$. samarangense samples may be a potential nutritional food colorant. Unsupervised PCA and supervised OPLS-DA chemometrics distinguished chemical features that affect dyeing properties beyond the observed color. These findings, along with growing data on natural dyes, could guide future research on sustainable colorants.
\end{abstract}

Keywords: natural colorants; ultrahigh-performance liquid chromatography-high resolution mass spectrometry (UHPLC-HRMS); metabolomics; GNPS; molecular networking

\section{Introduction}

Sustainability with sociocultural relevance reinvigorated research and development of natural dyes and pigments [1,2]. Additionally, with the detrimental effects on the environment and human health associated with synthetic dyes, there is a renewed interest in the discovery of natural biocolorants [1,2]. Guiding the discovery process is a wealth of literature on plant [3], fungi, and bacteria [4] and animal sources [5,6]. Exciting applications are being explored for leather tanning [7], food, and cosmetics [8,9], as well as in sensor technology [10] and the development of dye-sensitized solar cells [11].

In the Philippines, the promotion of natural dyes supports the livelihood of indigenous groups and highlights cultural heritage through their woven textiles [12]. Furthermore, the practice of traditional dyeing serves as a platform for promoting cultural heritage [12]. In line with their importance, the Philippine Textile Research Institute (PTRI) published a compendium detailing traditional and scientific knowledge on over one hundred dyeyielding plants $[13,14]$. To further promote sustainable dyeing, the existing list could be appended with colorants sourced from waste materials from food and timber production [1]. Plant biowastes had very little to no documented applications, such as peels from native fruits Syzygium samarangense (Blume) Merr. and Perry. (loc. makopa), Syzygium malaccense 
(L.) Merr. and Perry. (loc. makopang-kalabaw), Diospyros discolor Willd. (loc. mabolo), and the endemic Dillenia philippinensis Rolfe (lockatmon). Similarly, there is a need to explore the use of the outer bark of Eucalyptus deglupta Blume (Mindanao rainbow tree), utilized commonly for its pulp and timber [15].

Perceived color and application of natural dyes to textiles depend heavily on their chemical composition [16]. In terms of plant-derived colorants, specific classes of compounds (flavonoids, tannins, carotenoids, etc.) are known to impart color to fibers in the presence or absence of mordants [4,16]. Additionally, present in some dye baths are other small molecules such as hydrophobic lipids that could affect the interaction of the chromophores on fibers [17]. Untargeted small molecule analysis, therefore, is crucial to understand the complex color yielded by crude natural dyes [18]. LC-MS-based metabolomics presents a sophisticated platform for the sensitive detection, characterization, and comparison of small molecules present on natural dye samples [18]. Through stateof-the-art instrumentation in the form of ultra-high performance liquid chromatography in tandem with high-resolution mass spectrometry (UHPLC-HRMS), the mass spectra of small molecules can be acquired without extensive purification [19]. Data analysis using the cloud-based Global Natural Products Social Molecular Networking (GNPS) platform allows accessible and free matching to a community-curated spectral library for putative identification of metabolites [20]. In addition, molecular networking analysis indicates structural relationships of annotated metabolites with unidentified constituents that may be present on different dye samples [20]. The distribution of specific metabolites across groups of samples could also be further explored using multivariate statistics [21]. This study integrates LC-MS profiling, molecular networking analysis, and chemometrics to annotate the color palette yielded by biowaste dyes, and the strength of the metabolomics approach to compare spectral signatures across diverse samples and identify significant features that could be linked to similar or divergent dyeing properties. Because of these, newly identified biocolorants from S. malaccense, S. samarangense, D. discolor, D. philippinensis, and E. deglupta were not only analyzed side-by-side with each other, but also compared with the molecular fingerprint of a traditional source of yellow dye, Terminalia catappa L. (talisay).

\section{Results}

\subsection{Extraction of Biowaste Natural Dyes and Dyeing on Textiles}

The main driving force towards exploration of biowaste natural dyes is the desire to provide sustainable alternatives to synthetic dyes as well as plant-based sources that require months or even years of cultivation [4]. Furthermore, utilizing food wastes could result in profit among small- to large-scale enterprises even with limited investments in terms of capital [8,22]. In this research, we explore underutilized sources from fruit peels of S. malaccense, S. samarangense, D. discolor, D. philippinensis, and the outer bark of E. deglupta (Figure 1) that are easily accessible to different locals throughout the Philippines [23,24]. The highlighted extraction process was the decoction preparation based on the traditional method of many communities. The mentioned approach is relatively cheap, safe, and readily accessible compared with the use of organic of solvents [25].

Heated aqueous extraction was able to produce colorful solutions that changed colors in the presence of $\mathrm{FeSO}_{4}$, alum $\left(\mathrm{KAl}\left(\mathrm{SO}_{4}\right)_{2} \cdot 12 \mathrm{H}_{2} \mathrm{O}\right), \mathrm{CuSO}_{4}$, tartaric acid $\left(\mathrm{C}_{4} \mathrm{H}_{6} \mathrm{O}_{6}\right)$, and soda ash $\left(\mathrm{Na}_{2} \mathrm{CO}_{3}\right)$ mordants (Figure $\left.2 \mathrm{~A}\right)$. These fixatives were used in the pre-treatment of fabrics (pre-mordanting) and were also incorporated during dyeing process (metamordanting). As can be seen in Figure 3, the addition of mordants increased the interaction of the extracts with cellulose fiber and resulted in a diverse range of color. Exceptions are Syzygium fruit peels, whose color readily washes away from the fabric after the dyeing process. Observed colors are further described elsewhere (Table S1) in terms of their hue, saturation, and value coordinates. Significant coloration and overlap were observed among E. deglupta, D. philippinensis, and T. catappa. Annotation of chemical features from the biowaste extracts became the focus of the succeeding metabolomics investigation. 


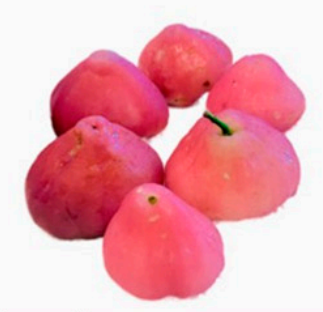

\section{Syzygium samarangense}

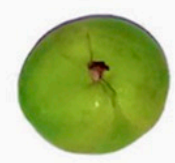

Dillenia philippinensis

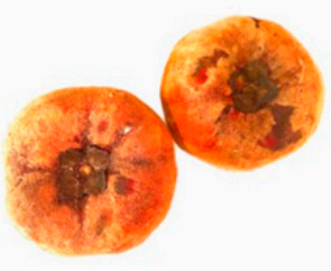

Diospyros blancoi

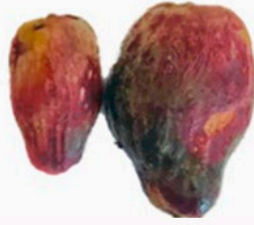

Syzygium malaccense

Figure 1. Plant sources of extracted natural dyes. Colorants were extracted from the fruit peel of S. samarangense, S. malaccense, D. philippinensis, and D. discolor, as well as the outer bark of E. deglupta. Resulting chemical profiles were compared with the hydrophilic dye from leaf decoction of T. catappa.

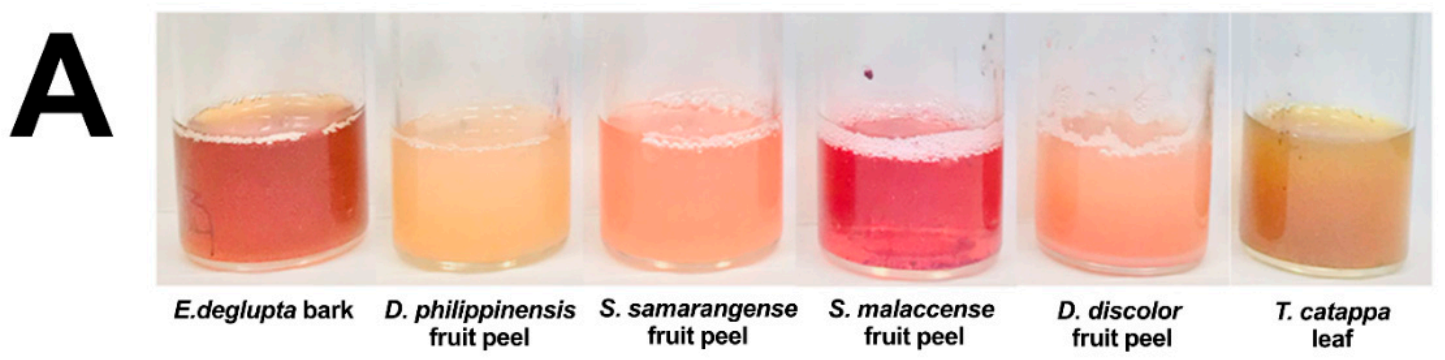

B S. malaccense fruit peel decoction

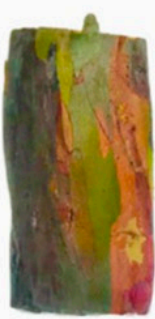

Eucalyptus deglupta

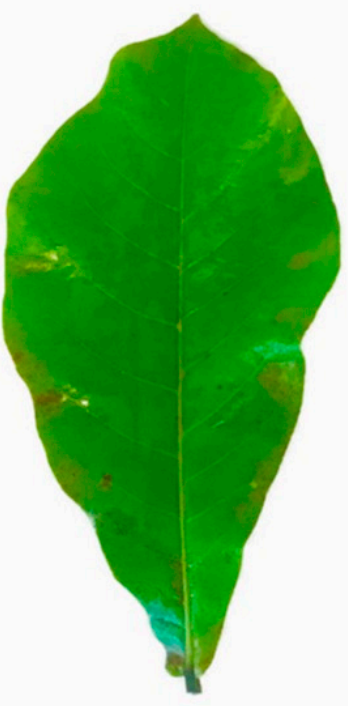

Terminalia catappa

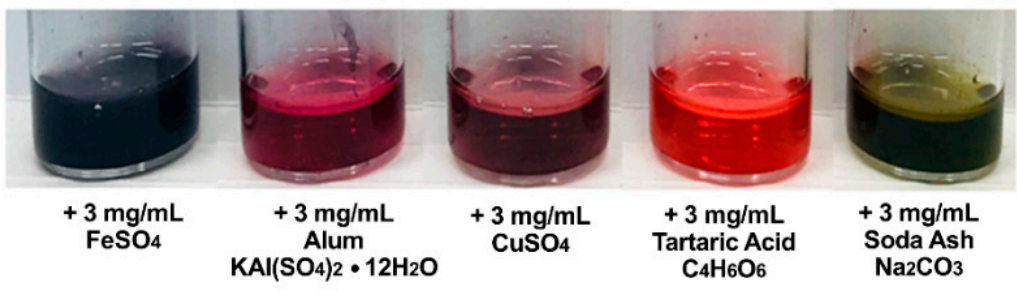

$3 \mathrm{mg} / \mathrm{mL}$

S. samarangense fruit peel decoction

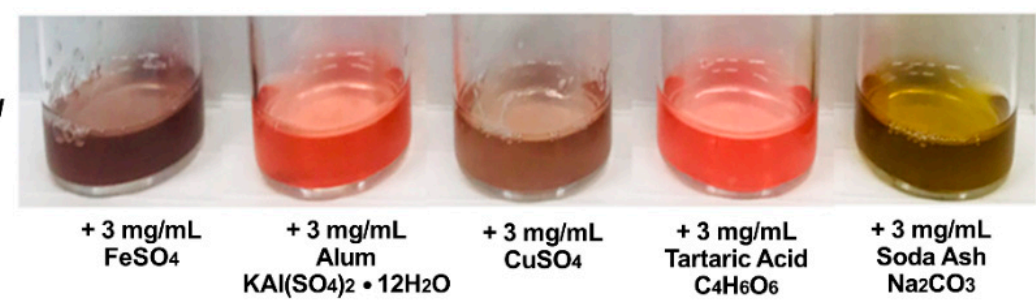

Figure 2. Extracted colorants from biowaste materials. Decoctions from five waste materials and the popular dye source T. catappa are displayed in (A). In addition, the significant effect of mordants on color is demonstrated in terms of Syzygium dyes in (B). Additional images from other dye samples can be found in Figure S1. 


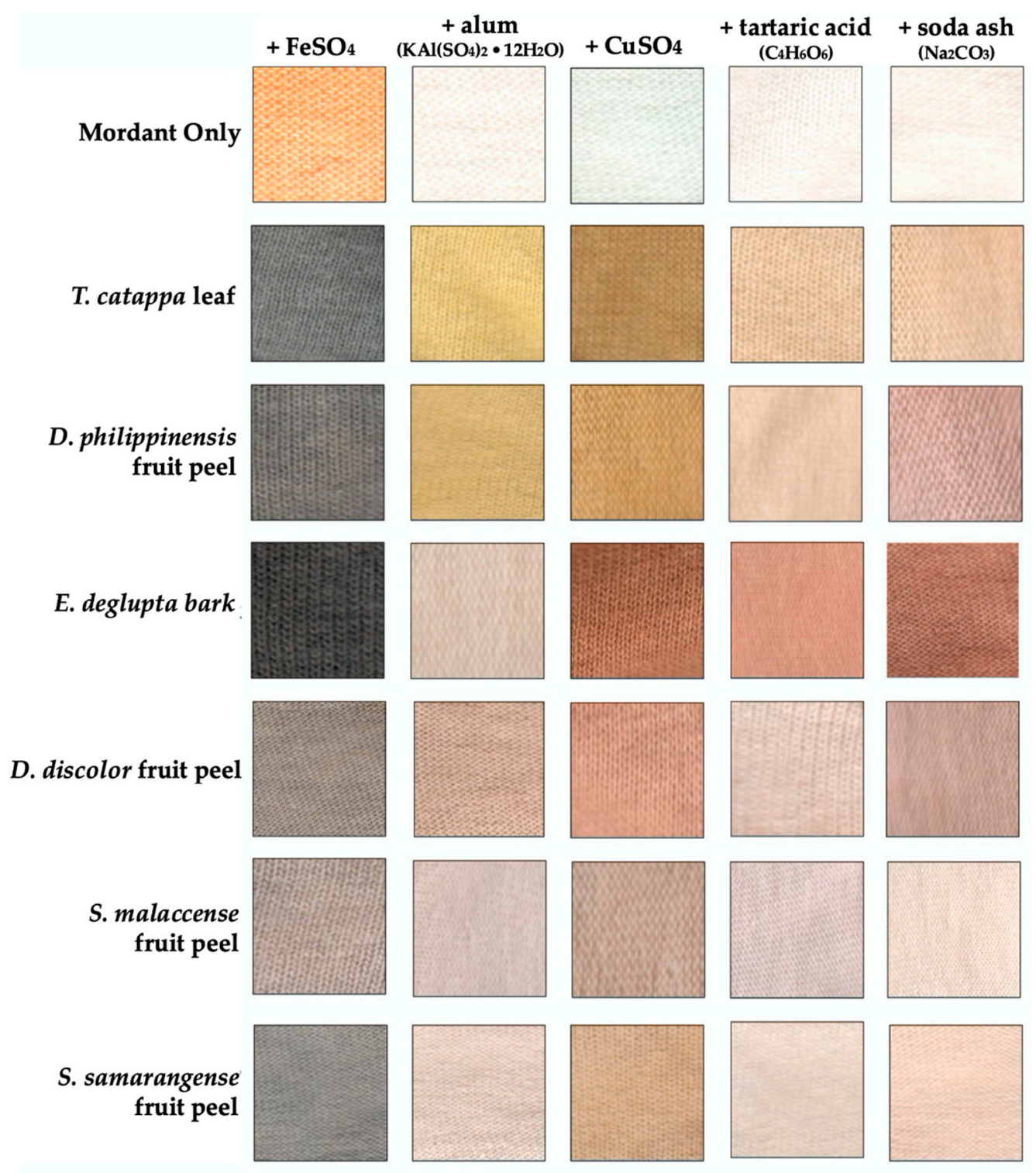

Figure 3. Color palette from the biowaste dyes applied in cotton using different mordants. Comparison of color is through the measured hue (color component), value (lightness), and saturation (intensity). Lighter color (low \%V value) is obtained in the presence of $\mathrm{FeSO}_{4}$, especially for E. deglupta and T. catappa (both black). D. philippinensis extract mordanted with alum also produced yellow comparable to the well-studied T. catappa. Interestingly, red-brown coloration was uniquely observed in E. deglupta with $\mathrm{CuSO}_{4}$ or alkali.

\subsection{UPLC ${ }^{\circledR}$-ESI qTOF Profiling, Molecular Networking and Structural Analysis of Small} Molecules from Extracted Natural Dyes

Similarities and contrast in the color schemes (Figure 3) motivated the metabolomics investigation of the samples. Reverse-phase LC-MS profiling showed the difference in the small molecule fingerprint of the biowaste dyes (Figure 4). Annotation of relatively abundant features was carried out through library search in GNPS. A wide range of compounds was putatively identified, including highly polar anthocyanidins, anthocyanins, sugars, amino acids, and other primary metabolites. In addition, diverse structures of flavonoids and tannin dyes were noted for most of the samples at $t_{R}=3.00-5.00 \mathrm{~min}$. Present only in $S$. samarangense are low molecular weight chalcones $\left(t_{R}=3.00-5.00 \mathrm{~min}\right.$, Figure 4F) immediately followed by highly retained lipids, and chlorophyll pigments and 
their catabolites (Figure 4A-F, $t_{R}=7.50-9.00 \mathrm{~min}$ ). Details supporting the annotation of these features are tabulated in Tables S2-S7 and Figures S2-S6.

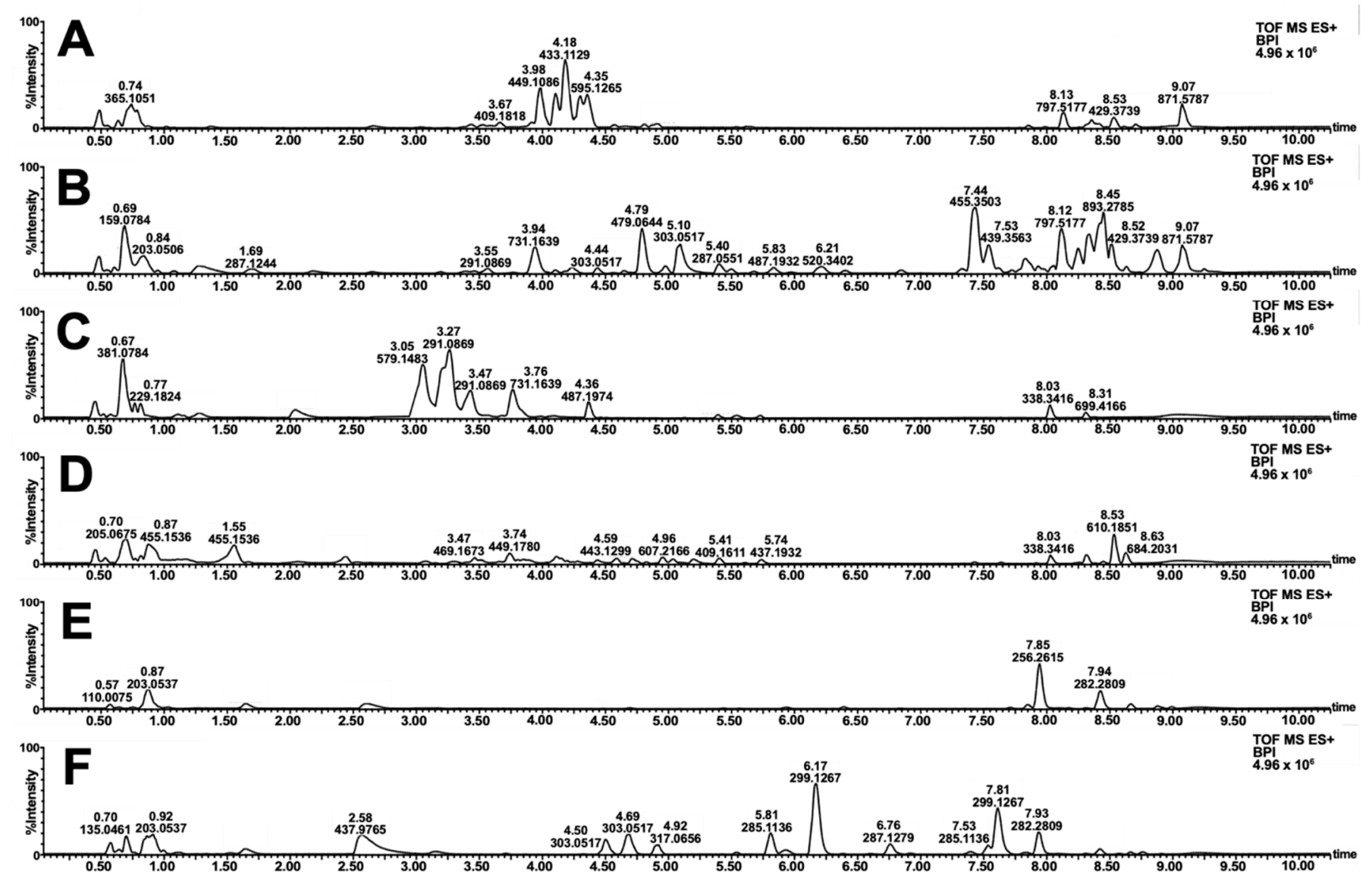

Figure 4. Base peak ion (BPI) chromatogram of extracted natural dyes. Full-scan profiles in the positive mode are shown for decoctions of T. catappa leaf (A) D. philippinensis fruit peel (B), E. deglupta bark (C), D. discolor (D), S. malaccense (E), and S. samarangense $(\mathbf{F})$ fruit peels.

Structural relationships among annotated and unidentified features were further explored through molecular networking analysis in GNPS [20]. In a molecular network such as in Figure 5A,B, precursor ions are represented as nodes, which are connected if spectral similarity among them exceeds a set threshold [20]. A cut-off value of 0.70 was used in the analysis, as suggested from previous reports. [26,27]. The cosine score calculated from experimental data is specified in the thickness of the edges connecting the nodes [26]. Since the fragmentation pattern arises from the molecular structure, spectral families hint at precursor ions that share similar backbone or functional groups. 

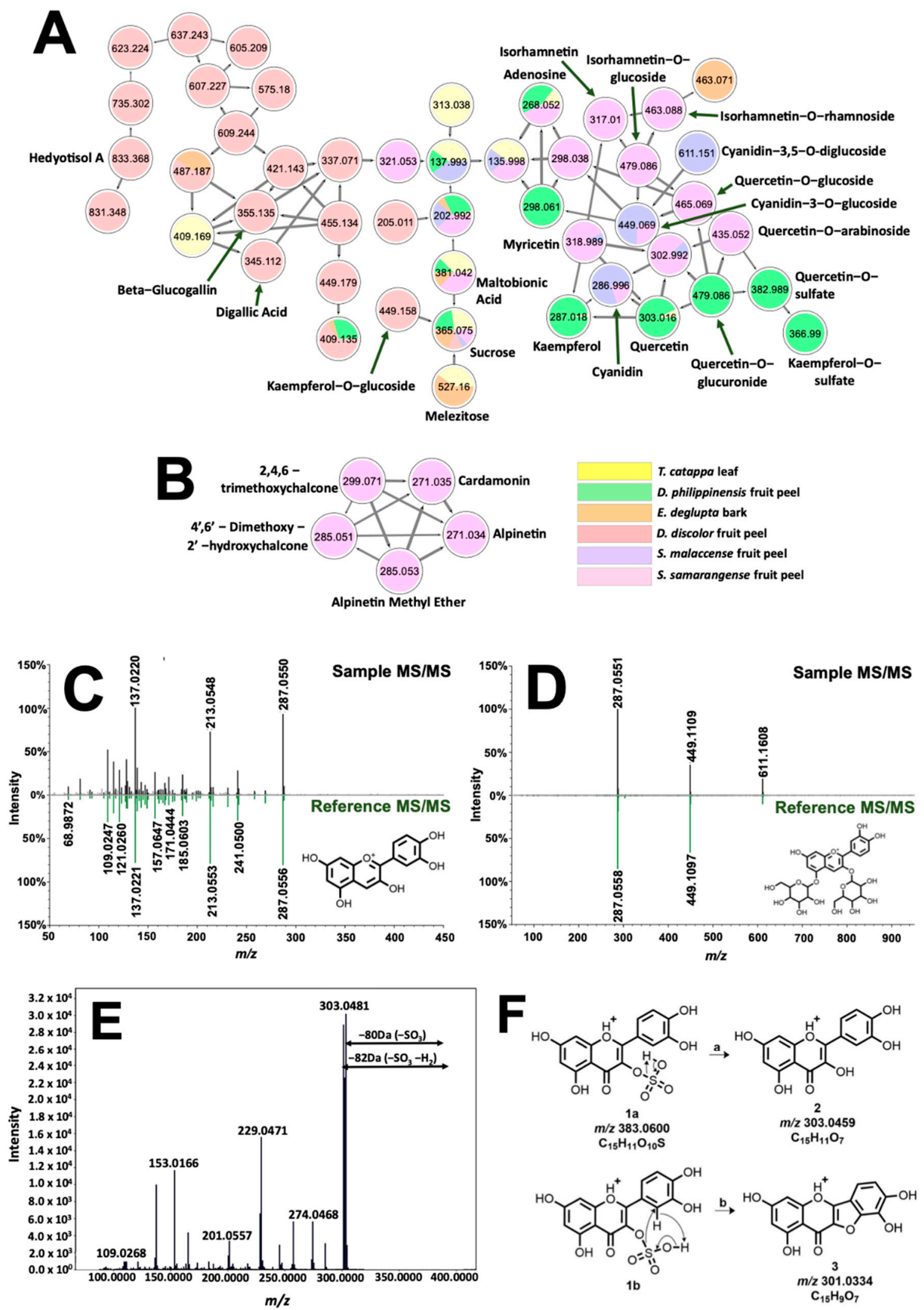

Figure 5. Molecular networking and identification of phenolic compounds from the extracted biocolorants. Structural relationship of flavonoids, sugars, and glycosylated and galloylated compounds are shown in (A). Different fragmentation schemes for chalcones in S. samarangense led to their exclusive clustering in (B). Tail-to-tail alignments for cyanidin and cyanidin-3,5-O-diglucoside are presented in (C) and (D), respectively. Meanwhile, MS/MS spectra associated with quercetin3-O-sulfate are presented in (E). Fragmentation analysis (F) suggested sulfate substitution on the hydroxyl at C-3 of quercetin. 
The molecular network in Figure 5A presents the occurrence of phenolic dye components such as anthocyanins and flavonols present in the samples. Annotated features (labelled accordingly) are associated with mirror matches such as in Figure 5C,D for cyanidin ( $t_{R}=1.05$ min., 0.31 ppm, cos score $=0.77$ ), and cyanidin-3,5-O-diglucoside $\left(t_{R}=1.05 \mathrm{~min}, 0.23 \mathrm{ppm}\right.$, cos score $\left.=0.87\right)$. Clustering of cyanidin with flavonols (quercetin, kaempferol, myricetin, and isorhamnetin) is expected due to similarities in molecular structure, giving rise to shared identical product ions formed from fragmentation routes such as retro-Diels Alder (RDA) and decarbonylation reaction [28]. Networking of glycosylated flavonol, anthocyanins, and their aglycones is attributed to intense product ion signals from the aglycone moiety as well as prominent neutral losses of 146, 162, and 178 Da from the elimination of rhamnose, glucose, and glucuronic acid along the glycosidic bonds, respectively [29]. Isobaric features with $\mathrm{m} / z 383.0600\left(\mathrm{t}_{\mathrm{R}}=8.41 \mathrm{~min}\right.$. and $\left.9.07 \mathrm{~min}\right)$ as well as $m / z 367.0118\left(t_{R}=8.87 \mathrm{~min}\right.$.) have no library hits but were annotated based on their networking with both quercetin and kaempferol (Figure 5A). Neutral loss of 80 Da between precursor ion and $m / z 303.0446$ hinted at a sulfate modification on one of the hydroxyl groups of quercetin [30]. Location of substitution is deduced using the prominent signal of $\mathrm{m} / \mathrm{z} 301.0334$ present only on this isomer (Figure 5F). Figure 5E explains the formation of this product ion from the simultaneous loss of $\mathrm{SO}_{3}$ and $\mathrm{H}_{2}$ of the precursor ion. Fusion of ring systems $\mathrm{B}$ and $\mathrm{C}$ of the flavonoid is highly likely if the sulfonation site is at C-3. Therefore, annotations for $m / z 303.0446$ and 367.0118 are quercetin-3-O-sulfate (1.93 ppm) and kaempferol-3-O-sulfate $(0.90 \mathrm{ppm})$, respectively.

Analysis of phenolic dyes in Figure 5A were then extended to other precursor ions that include a sugar group in their fragmentation pattern. For D. discolor, a unique precursor ion (Figure S7) with $m / z 355.0651$ fragmented to produce $m / z 203.0508$ associated with sodiated hexose, $[\mathrm{Hex}+\mathrm{Na}]^{+}$. In addition, the neutral loss of $152 \mathrm{Da}$ from both $\mathrm{m} / \mathrm{z} 355.0651$ and $m / z 345.0215$ precursor ions indicated gallate substitution [31]. Because of this, annotation provided for the former is glucogallin $(2.76 \mathrm{ppm})$, whereas the latter, which exhibited $\mathrm{m} / \mathrm{z}$ $153.0192\left(\mathrm{C}_{7} \mathrm{H}_{5} \mathrm{O}^{+}\right.$, Figure $\left.\mathrm{S} 8\right)$, is characterized to be digallic acid (2.90 ppm). Annotation of these low molecular weight derivatives of gallic acid is important as they could impart black coloration in the presence of $\mathrm{FeSO}_{4}$ [32].

Compounds with high molecular weight showed distinct clusters with molecular networking. Spectral families in Figure 6C,D include precursor ions common between T. catappa and D. philippinensis, which can be implicated in the comparable color profiles resulting from the two samples. GNPS annotated vitexin (Figure 6C) in D. philippinensis, whereas isovitexin (Figure 6D) gave high signal intensity in T. catappa. These isomers yielded identical product ions characteristic of C-glycosylated flavonoids [33]. Vitexin is differentiated by a high intensity of dehydration reaction products from C-8 glycosylated flavonoids [33,34]. Cross-ring cleavage of the pyran ring, on the other hand, is favored for C-6 glycosylated flavonoids as can be seen for isovitexin (Figure 6D) [33,34]. This difference in product ion intensities was used to characterize the glycosylation sites on the other analogs (Figure 6A). Unmatched precursor ions with $\mathrm{m} / \mathrm{z} 579.1496$ displayed a similar fragmentation pattern as vitexin (Figure 6E). Neutral loss of $146 \mathrm{Da}$ and the presence of $m / z$ 147.0436 were linked to the presence of a rhamnose group (Figure 6F) [29]. The location of this modification was also identified to be C-2 of the pyran ring, based on one of the cross-ring cleavage products with $m / z 459.1169$ (Figure 6F) [33]. Hence, the annotation given to $m / z 579.1496$ is vitexin-2"O-rhamnoside (1.55 ppm). A similar approach was used to characterize $m / z 585.1265$ and $m / z$ 601.1261, which resembles the fragmentation pattern of vitexin and isoorientin, respectively. Again, neutral loss of $152 \mathrm{Da}$, and intense $m / z 153.0192$ product ion resulted in the annotation of the precursor ions as vitexin-2"O-gallate $(\mathrm{m} / \mathrm{z} 585.1265,3.59 \mathrm{ppm})$ and isoorientin-2"O-gallate $(\mathrm{m} / \mathrm{z} 601.1261$, $3.66 \mathrm{ppm}$ ). Vitexin-O-sulfate was also characterized based on its network connection with vitexin, and neutral loss of $80 \mathrm{Da}$. Position of the sulfate group cannot be determined due to the absence of diagnostic productions. 

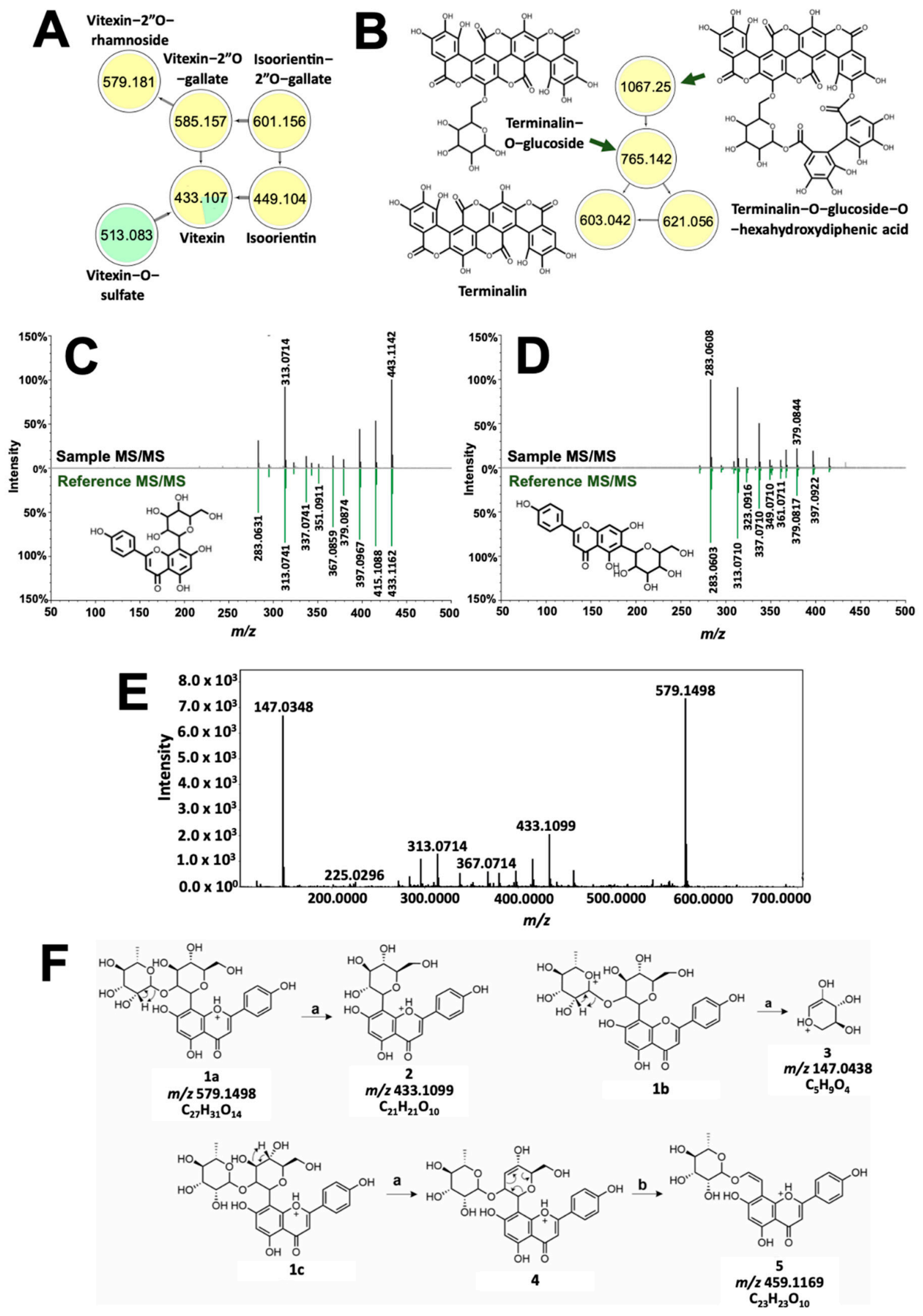

Figure 6. Structural analysis of dye molecules common to T. catappa and D. philippinensis. Molecular network of flavotannins and ellagitannins are depicted in (A) and (B), respectively. GNPS also differentiated positional isomers vitexin (C) and isovitexin (D). Meanwhile, tandem MS spectrum of $m / z 579.1496$ showed huge similarity with that of vitexin (E). Fragmentation analysis suggest the presence of rhamnosyl substituent at C2" of vitexin (F). For the reactions, (a) is the remote H-rearrangement, and (b) is the RDA reaction. 
Figure $6 \mathrm{~B}$, on the other hand, showed the presence of additional high molecular weight tannins that are unique to T. catappa. Presence of $m / z 303.0161$ (Figure S9) hinted to an ellagic acid core that served as the basis for the structural characterization of terminalin ( $m / z$ 603.0092, 0.61 ppm, Figures S9 and S10), a known ellagitannin from Terminalia sp. [35,36]. Using the MS/MS profile of terminalin, two other nodes in the cluster were putatively assigned as terminalin-O-glucose-O-hexahydrodiphenic acid ( $\mathrm{m} / \mathrm{z} 1066.0640,1.27 \mathrm{ppm})$ and terminalin-O-glucoside $(\mathrm{m} / \mathrm{z} 765.0583,173 \mathrm{ppm})$ based on the subsequent neutral loss of hexahydroxydiphenic acid (302 Da) and a glucose (162 Da) unit (Figures S11-S14) [31]. These two compounds have not been previously reported in T. catappa.

Meanwhile, the tannin profile of $D$. philippinensis fruit peel is comparable to E. deglupta bark. The network in Figure 7A contains $m / z$ 579.1483 (Figure 7B), which matches with procyanidin B2 on the GNPS library. Remaining nodes that were unidentified were annotated as proanthocyanidins, consisting of epicatechin, epigallocatechin, and epiafzelechin subunits based on neutral losses and product ions derived from quinone-methide (QM) fragmentation [36]. Additional reactions that supported the structural analysis of these phenolic compounds include RDA, benzofuran forming fusion (BFF), and heterolytic ring fusion (HRF) reactions [36] (Figures S15 and S16). Structural analysis of $m / z 731.1584$ is shown in Figure 7C. Presence of epicatechin subunits is supported by the detection of $m / z 289.0714$ product ion derived from the QM cleavage of the non-hydrolyzable backbone. In addition, the presence of gallate substitution was inferred from neutral loss of $152 \mathrm{Da}$ forming $\mathrm{m} / \mathrm{z}$ 579.1154. The exact position was determined based on the higher relative intensities of the RDA products $(m / z 427.1002$ and $m / z$ 409.0907) compared with $m / z 519.1154$ (loss of galloyl). Due to extensive hyperconjugation of the resulting product, it is well established that RDA reaction is favored over gallate elimination if the top-unit is galloylated [37,38]. Annotation for $m / z$ 731.158, therefore is epicatechin-3-O-gallate epicatechin (3.09 ppm), which resembles the structure of complex proanthocyanidins common to T. catappa and D. philippinensis (Figure 7).

Interestingly, small molecular weight flavan-3-ols that are precursors to complex tannins [36] were found to be significantly abundant in E. deglupta (Figure 7D). This observation is important because catechin and epicatechin are known to give red-brown coloration to textiles in the presence of $\mathrm{CuSO}_{4}$ mordant [39]. This shade was observed only on cotton fiber dyed with E. deglupta extract (Figure 3). Annotation of similar and unique features among dye samples prompted further examination of their chemical profile in terms of multivariate statistics.

\subsection{Chemometrics Analysis of Natural Dye Samples}

Unsupervised multigroup analysis in XCMS Online unraveled the molecular relationships between various biowaste colorant sources. Non-parametric principal component analysis (PCA) showed that the first two principal components (PCs) only accounted for $45.37 \%$ of the total variance in the chemical profiles, prompting the consideration of PC 3 (16.45\%; Figure $8 \mathrm{~A})$. Centering and $\log$ transformation was also carried out to account for the heteroscedasticity (i.e., inconsistent variance across concentration levels) of LC-MS data [40]. Putatively identified compounds from the GNPS molecular networking analysis such as flavonoids served as basis of comparison of these biocolorant sources. Various intensities of these compounds could likely influence the perceived color of the extract with or without mordant. 

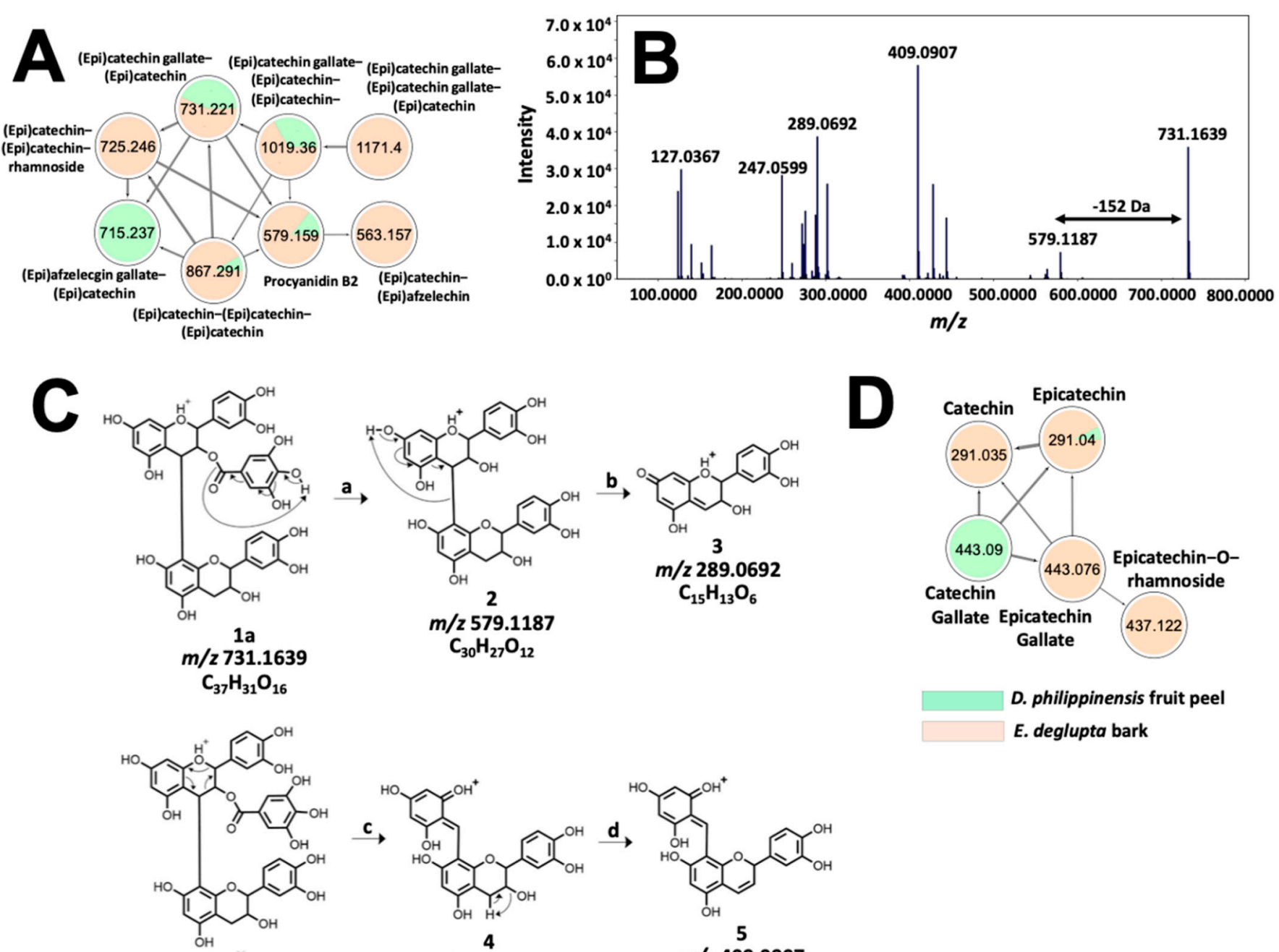

1b

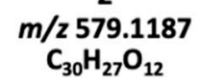

$\mathrm{C}_{15} \mathrm{H}_{13} \mathrm{O}_{6}$

D. philippinensis fruit peel

E. deglupta bark

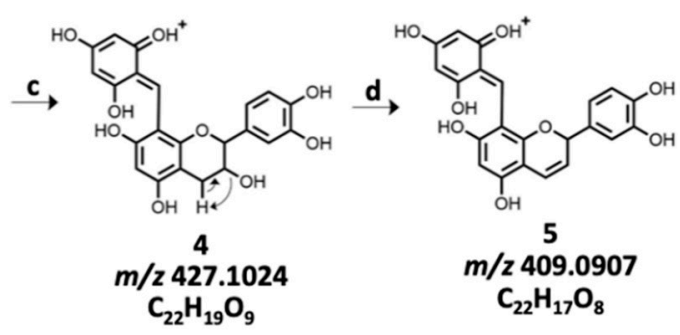

Figure 7. Molecular networking and fragmentation analysis of proanthocyanidins common to D. philippinensis and E. deglupta. Clustering of complex tannins is shown in (A); tandem MS spectrum of $m / z 731.1667$ is presented in (B) and served as the basis for fragmentation analysis that characterized the precursor ion as epicatechin-O-gallate-epicatechin (C). On the other hand, a smaller network of flavan-3-ol and their galloylated and glucosylated analogs is described in (D).

Plant extracts spread in three distinct regions (Figure 8A): R1 (PC1: -25.0 to -5.0, PC2: 5.0 to -2.5 , PC3: 15.0 to -20.0 ), R2 (PC1: 0.0 to 15.0, PC2: 7.5 to 25.0, PC3: 0.0 to 5.0), and R3 (PC1: 0.0 to 10.0, PC2: 0.0 to $-20.0, \mathrm{PC} 3: 15.0$ to -20.0 ). Major variance contributors are phenolics, particularly flavonoids and their glycosylated derivatives. These compounds along with lipid analogs and several other unidentified metabolites falling within the $\mathrm{m} / \mathrm{z} 200$ to 800 mass range contribute greater than or equal to $1.00 \%$ of the total variance observed in PC1 and PC2 (Figure 8B, data points in red). An example of lipid analogs identified by XCMS Online and molecular networking is dilinolein $(\mathrm{m} / z$ 613.4847, $p$-value: $1.92 \times 10^{-8}$ ), which is found only in T. catappa and D. philippinensis extracts. Additionally, the same set of compounds account for most of the variance in PC3 (data not shown). Although these compounds greatly contribute to the spread of data in PCA, they do not directly cause the observed color of the extracts but may influence solubility. For lipids, further studies are necessary to verify their effects on the dye properties. 


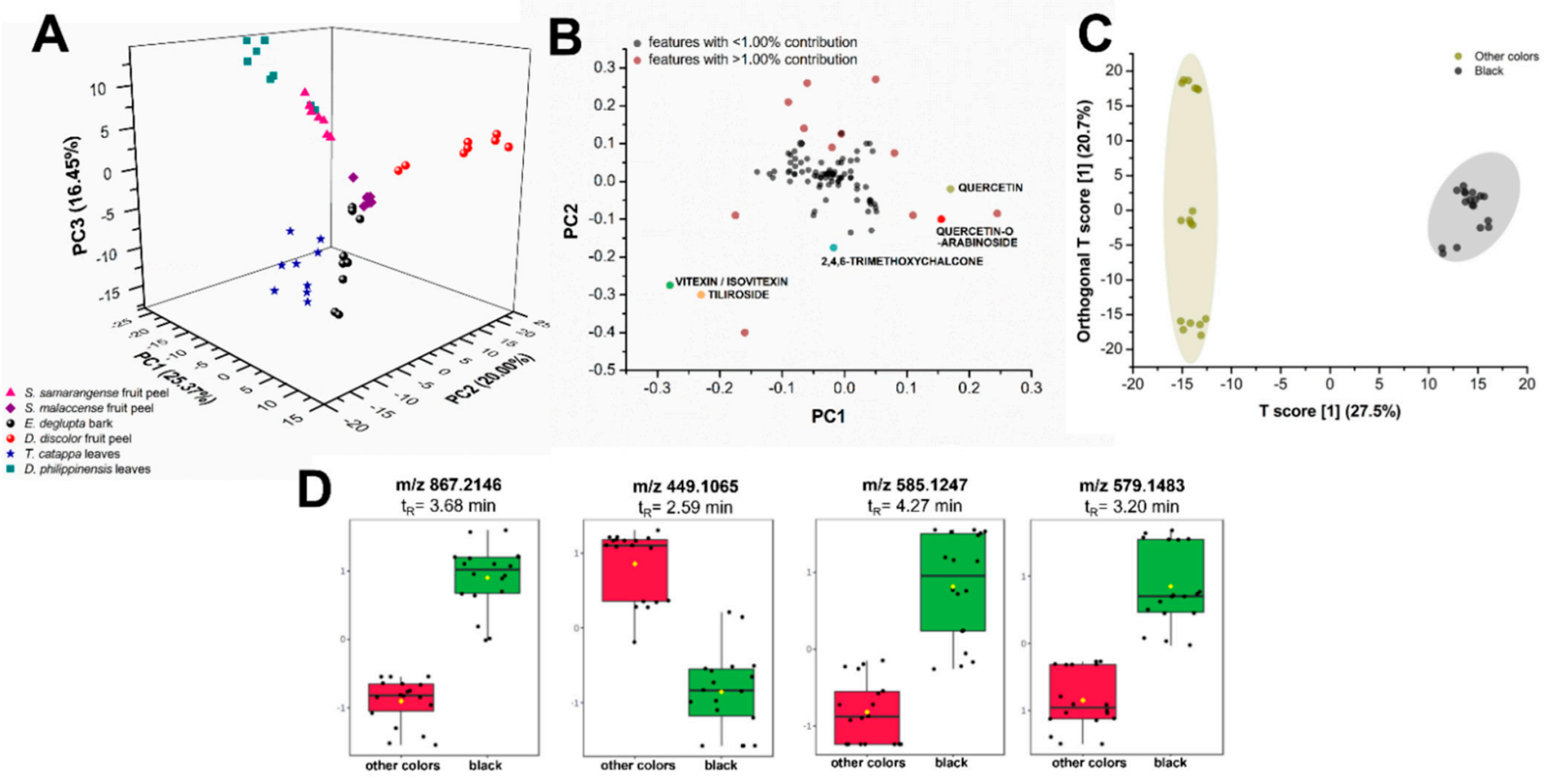

Figure 8. Comparative statistical analyses of metabolite profiles of plant biowaste sources. Unsupervised principal component analysis (PCA) (A) with its log-transformed loadings plot (B) and supervised OPLS-DA (C) show distinct separation between samples according to metabolite constituents and their produced color upon reaction with $\mathrm{FeSO}_{4}$ mordant. Putatively identified flavonoids (colored data points) were among the heavily contributing features (B) to the dispersion of samples in the PCA scores plot. Samples that produce the black color such as extracts from E. deglupta bark, D. philippinensis peel, and T. catappa leaves show the upregulation of some polyphenols (D) such as $m / z 867.2146$ (epicatechin), $m / z 579.1483$ (procyanidin B2), and m/z 585.1257 (vitexin-2"-O-gallate).

Leaf extracts from T. catappa and D. philippinensis cluster in R1, with the latter exhibiting a bimodal distribution (Figure 8A). Clustering in $\mathrm{R} 1$ is expected from leaf samples due to the presence of chlorophyll pigments and their catabolites in the form of pheophytin and pheophorbide. Moreover, the effect of phenolics in R1 can only be observed when PC3 is considered (Figure S17). It is interesting to note that D. discolor fruit peels (R2) did not cluster with Syzygium fruit peels (R3) in Figure 8A despite physical similarities, highlighting the effect of the presence and abundance of key flavonoids in group behavior. The abundance of known colored compounds such as flavonoids in certain extracts could also influence the observed color. However, PCA cannot predict the resulting color upon reaction with a mordant during textile applications.

Box-and-whisker plots (Figures S18-S23) also show relative abundances of putatively identified phenolics that have known contributions to dye production. Table 1 summarizes these chemical features that contribute significantly to the behavior of samples observed in PCA. Vitexin/isovitexin is highly abundant in T. catappa leaf and D. philippinensis fruit peel extracts. Meanwhile, a compound annotated by GNPS to be unique to $S$. samarangense fruit peel is 2,4,6-trimethoxychalcone, a flavonoid analogue that has a known yellow color [41]. However, this compound is highly hydrophilic and does not interact well with the fabric and the mordant. Another compound that is also abundant in S. samarangense fruit peel is quercetin. Despite the ubiquity of this compound in terrestrial natural products [42], it contributes $4.25 \%$ in total variance, and is found in relatively low abundance in $D$. discolor fruit peel compared with $S$. samarangense. Similarly, its glycosylated derivative, quercetin-O-arabinoside is highly abundant in S. samarangense but absent in D. discolor and $D$. philippinensis. These compounds are also highly hydrophilic and may have contributed to the low intensity or absence of yellow coloring when S. samarangense is reacted with 
alum. Tiliroside, a glycosylated flavone, is detected only in the fruit peel of D. philippinensis and does not have any reported use as a textile colorant.

Table 1. Highly significant and variable chemical features determined by XCMS Online.

\begin{tabular}{ccccc}
\hline Compound & Mass $(\mathrm{m} / z)$ & $p$-Value ${ }^{\mathbf{1}}$ & Contribution to Variance (\%) $^{\text {Source }^{\mathbf{2}}}$ & T. catappa, D. philippinensis \\
\hline Vitexin/Isovitexin & 433.1 & $8.81 \times 10^{-8}$ & 5.12 & S. samarangense \\
\hline 2,4,6-trimethoxychalcone & 299.1 & $2.89 \times 10^{-8}$ & 3.09 & S. samarangense \\
\hline Quercetin & 303.1 & $6.05 \times 10^{-5}$ & 4.25 & S. samarangense \\
\hline Quercetin-O-arabinoside & 435.1 & $7.18 \times 10^{-9}$ & 1.76 & D. philippinensis \\
\hline Tiliroside & 595.1 & $3.09 \times 10^{-10}$ & 4.03 &
\end{tabular}

${ }^{1}$ Highly significant features only ( $p$-value $\left.<0.0001\right) .{ }^{2}$ Sources where the compound is detected to be most abundant.

Furthermore, the presence of certain metabolites and their effect on the produced coloration were highlighted by orthogonal projection to latent structures discriminant analysis (OPLS-DA). Extracts that produce black coloration upon addition of $\mathrm{FeSO}_{4}$ mordant distinctively separate from samples that do not (Figure 8C). Polyphenols with masses $\mathrm{m} / \mathrm{z}$ 867.2146, 579.1483, and 585.1257 were putatively identified as epicatechin, procyanidin B2, vitexin-2"-O-gallate (Figure 8D), respectively. These compounds are associated with the production of black coloration in complexation reactions with iron mordants. Flavonoid isoorientin is present in T. catappa and D. philippinensis, both of which are producing black coloration with $\mathrm{FeSO}_{4}$ mordant. However, it is found to be absent in E. deglupta, another black-producing extract. This suggests that isoorientin, despite its relative abundance in other black-producing biowaste sources, is not a contributing feature in OPLS-DA.

\section{Discussion}

Chemistry of the colors of natural dyes is due to the presence of light-absorbing molecules in the crude extracts [4]. These organic compounds have chromophore motifs with alternating single and double bonds [43]. Extensive conjugation decreases the energy needed to promote electrons from the highest occupied molecular orbital (HOMO) to the lowest unoccupied molecular orbital (LUMO), thereby resulting in absorbance of wavelengths within the visible range of the spectrum [43]. In addition, the presence of auxiliary groups $\left(-\mathrm{OH},-\mathrm{NH}_{2},-\mathrm{CH}_{3}\right)$ also affects the wavelength of energy absorbed by natural dyes [43]. Detailed studies explored the effect of solvent, $\mathrm{pH}$, and mordants on the color and interaction of natural dyes in solution and/or in textiles [44-48]. This existing knowledge on the structure and physical chemistry of plant colorants guided the screening of biowaste extracts as natural dyes through metabolomics.

Identification of pigment classes such as flavonoids, tannins, and chalcones accounted for the colors obtained from the dyestuffs. These compounds were easily extracted as decoctions, with hydrogen bonding interactions with polyphenolic compounds [4]. Aside from its role in extraction, the chosen solvent significantly influenced color such as the strong red obtained from Syzygium fruit peel [44,48]. In silico simulations of dyes in the gas phase predicted blue color in vacuum that is shifted to red wavelengths in the presence of explicit water and methanol solvent [44]. The importance of solvent lies in its role in increasing the polarizability of dye molecules and incorporating thermal fluctuations and conformational variability in the molecules, resulting in the experimental observations $[45,49]$. Considering this, the resulting spectra of anthocyanins have been correctly predicted with explicit models of water or methanol solvent [44]. In addition, solution $\mathrm{pH}$ can slightly, or drastically, change the structure of the chromophore [4]. For cyanidin, saturation of red color is most intense at highly acidic conditions ( $\mathrm{pH}$ 3.0), where the flavylium cation of the anthocyanidin dominates [49]. In the presence of alkaline $\mathrm{Na}_{2} \mathrm{CO}_{3}$, the flavylium ion is converted to an unstable hemiketal, which further reacts to yield a chalcone [49]. Equilibrium among these different species explained the green dye bath from $\mathrm{S}$. malaccense pre-mordanted with $\mathrm{Na}_{2} \mathrm{CO}_{3}$ (Figure 3). In contrast, yellow green 
color was observed in S. samarangense due to the inherent presence of yellow chalcones not present in S. malaccense (Figure 3).

Even with pre- and meta-mordanting, extracts from S. samarangense and S. malaccensse did not impart significant coloration to textiles (Figure 3). Limitation on the use of the Syzygium samples can be attributed to the higher solubility of anthocyanins in the dispersion medium compared with the cellulose fibers $[50,51]$. A previous report circumnavigated this using $\mathrm{SnCl}_{2}$ at acidic conditions [52]. This mordant, however, is rarely used by Filipino artisans, and therefore was not explored in the study. Interestingly, the presence of chalcones did not impart significant yellow coloration to cotton dyed with $S$. samarangense extract [41]. Chalcones gave the most intense signals in the base peak chromatogram of the samples (Figure 4F), although signal intensities do not necessarily correlate with the abundances of these compounds in the crude mixture. It is also possible that the presence of anthocyanins reduces the dyeing capabilities of chalcones through the formation of colloidal dispersion [53], although this aspect is no longer explored in this work.

On the other hand, the presence of flavonoids (quercetin, vitexin, their glucosides) imparted yellow coloration for both $D$. philippinensis and T. catappa. The presence of these flavonoids was corroborated by the UV-Vis absorbance profile showing maximum absorption wavelengths at 275 and $373 \mathrm{~nm}$ corresponding to the cinnamoyl group (rings $\mathrm{A}$ and C) and the benzoyl functional group (rings B and C) of the flavonoids, respectively [54] (Figure S24). In terms of solvent effects, polar protic solvents stabilize flavonoids through H-bonding interactions, resulting in a slight shift in the absorbance towards longer wavelengths [55]. A more pronounced red shift emerges in the presence of mordants, which stabilizes flavonoids through metal-to-ligand charge transfer [56-63]. Hyperchromic shift was also observed on the dyebaths (Figure S24) indicating possible coagulation of dye molecules in the presence of mordant [53]. Such aggregation promotes the dyeing process and the mordants follow this up by effectively fixing the dye molecules on the cellulose fiber [51].

Previous reports showed that metal ions $\left(\mathrm{Fe}^{2+}, \mathrm{Al}^{3+}\right.$, and $\left.\mathrm{Cu}^{2+}\right)$ through three hydroxylcontaining sites on the flavonoid structure [56-63]. Complexes with 1:2 stoichiometry between metal ion and flavonoid are formed through chelation in the oxygen atoms of C3C4 (ring C) or between C4-C5 (ring A-C) [57-62]. Meanwhile, a stable 1:1 complex is formed through coordination at $\mathrm{C}^{\prime}-\mathrm{C} 4^{\prime}$ (ring B) [57-62]. For both T. catappa and D. philippinensis, annotated flavonoids existed in the O- and C-glycosylated forms. These derivatives have been previously noted to have lower affinity for mordants, especially if the glycosylation site is a hydroxyl group involved in complexation [63]. Sugar chain/s of glycosylated flavonoids do not contribute to the HOMO and LUMO but enhance nucleophilicity via electron donation, especially if the position of the sugar group is at C7 [63].

Contrary to T. catappa and D. philippinensis, E. deglupta did not produce yellow in the presence of alum mordant (Figure 3). Highly intense features in E. deglupta are epicatechin and catechin that lack carbonyl group at $\mathrm{C} 4$, which is crucial to chelation with $\mathrm{Al}^{3+}$ [56] Sole binding site for metal is the catechol group that could interact with $\mathrm{Cu}^{2+}$ ions. This weak catechol-metal complex which becomes oxidized gives red-brown shades observed in textiles due to catechinone [64]. For T. catappa and D. philippinensis, a local maximum at $293 \mathrm{~nm}$ emerged from the oxidation of quercetin that was implicated to the brown color in the presence of excess $\mathrm{CuSO}_{4}$ [61].

The complexation process is also responsible for black shades obtained from the decoctions in the presence of $\mathrm{FeSO}_{4}$ [65]. The dark color could be from the complexation of $\mathrm{FeSO}_{4}$ with either gallic acid or catechin $[31,66]$. The computational study also highlights the role of water molecules in maintaining stable octahedral geometry across the metal ion during the complexation process [59].

Multivariate analysis using PCA [67] and OPLS-DA [68] was able to verify the effect of known color-producing compounds such as flavonoids and flavotannins. However, factors such as ionization efficiency and concentration may affect the chemical features detected by these statistical methods. For PCA, most of the features that heavily contribute 
to variance may not directly produce a color nor complex with mordants during the dye process. While powerful, PCA can only reveal differences between samples if the features are major contributors to the total variance $[67,68]$. OPLS-DA compensates for this by distinguishing the samples based on group-specific characteristics, in this case, dye molecules and their associated color [68]. The distinction between the extracts is their explicit production of black coloration upon complexation with iron mordant. Black coloration was obtained from $\mathrm{Fe}^{2+}$-complexed extracts from E. deglupta, D. philippinensis, and T. catappa and their separation from S. samarangense, S. malaccense, and D. discolor was explained by the abundance of epicatechins, procyanidins B2, and vitexin-2"-O-gallate.

Future research could also look at the effect of non-pigment molecules on the dyeing properties of crude samples. A molecular network in Figure S25 contains high molecular weight phosphocholine type lipids detected mostly on D. philippinensis fruit peel.

Multiple reports describe beneficial effects of liposome formation on the dyeing process, especially on wool fibers [69-71]. The presence of lipids was shown to promote dye interaction with fibers through vesicle formation and release that can be fine-tuned by adjusting $\mathrm{pH}$ or dyeing temperature [71]. Adding to this, liposome-assisted dyeing promotes more sustainable energy use since it employs milder dyeing conditions at lower temperatures (usually $10.0^{\circ} \mathrm{C}$ lower than conventional processes) [71]. With higher concentration of lipids, however, liposomes exhibit greater stability, and the dyeing properties of the extracts decrease [71]. Succeeding work could use targeted mass spectrometry-based metabolomics towards quantifying and understanding their effect on the color yield of different natural dyes.

Furthermore, the results of the study also highlight potential challenges associated with the use of some of the biowaste dyes. Chief dye molecules annotated were flavonoids known to have poor photostability [57]. To determine lightfastness, additional experiments could investigate the optimum concentrations of metal ion and dye that will minimize photobleaching [72]. Use of ionic [73] and biomordants [74] could also be explored together with the incorporation of UV-quencher compounds such as nickel hydroxylarylsulfonate [75].

These suggestions could be included in future research to address the major limitation of this work in terms of assessment of the fastness properties of the samples. Despite this, the major contribution of this metabolomics study is on the preliminary mass spectral data of biowaste natural dyes that will be deposited in GNPS. This additional information on natural dyes could be used by other groups exploring unique and sustainable sources of colorants.

To summarize, LC-MS based metabolomics was able to guide rapid screening of biowaste materials as alternative source of colorants. Comparative analysis in terms of fragmentation pattern and chemometrics also provided insights behind the color produced by the samples. Results of untargeted profiling also revealed the presence of highly intense compounds such as anthocyanins, phosphocholine lipids, and flavonoids that could influence color during and after the dyeing process. Overall, small molecule fingerprinting provided extensive chemical information on natural dyes that could be useful for future research in process development, quality control, and the discovery of sustainable hues.

\section{Materials and Methods}

\subsection{Chemicals and Reagents}

Acetonitrile and water solvents used in sample extraction and chromatography were from Merck (Darmstadt, Germany). Formic acid incorporated in the mobile phase, as well as $\mathrm{CuSO}_{4} \cdot 5 \mathrm{H}_{2} \mathrm{O}, \mathrm{KAl}\left(\mathrm{SO}_{4}\right)_{2} \cdot 12 \mathrm{H}_{2} \mathrm{O}$ (alum), and $\mathrm{FeSO}_{4} \cdot 2 \mathrm{H}_{2} \mathrm{O}$ used in the dyeing experiments were acquired from Thermo Fisher Scientific (Waltham, MA, USA). Meanwhile, standard compounds were sourced from Sigma Aldrich (St. Louis, MO, USA) 


\subsection{Extraction of Natural Dyes}

Fruits of S. malaccense and D. discolor as well as bark of E. deglupta were collected from the municipality of Naga, Zamboanga Sibugay. Meanwhile, fruit peels of D. philippinensis, and S. samarangense, and leaf of T. catappa were sampled inside the UP Diliman Campus. Specimens were identified at the Jose Vera Santos Memorial Herbarium, Institute of Biology, UP Diliman.

Natural dyes were then immediately extracted by soaking fresh plant parts in water following the $1: 20(\mathrm{~g} / \mathrm{mL})$ ratio. The mixture was heated at $100^{\circ} \mathrm{C}$ for $30 \mathrm{~min}$, after which the solutions were filtered and lyophilized. Appropriate amounts of dried extracts were weighed and resuspended in 50:50 acetonitrile: water to obtain a final concentration of $3 \mathrm{mg} / \mathrm{mL}$ for LC-MS analysis.

\subsection{LC-MS Analysis}

Instrumental analysis was performed based on a method that has been optimized for natural dyes [18]. Profiling of extracts were carried out using Waters Acquity ${ }^{\circledR}$ Ultrahigh Performance Liquid Chromatography (UPLC ${ }^{\circledR}$ ) system in tandem with a Xevo G2-XS quadrupole time-of-flight mass spectrometer. Detection of small molecules was performed in the positive mode electrospray ionization (ESI) source. To obtain optimum separation of metabolites, chromatographic separation involved injection of $3.5 \mu \mathrm{L}$ extracts in a Waters Acquity ${ }^{\circledR}$ CSH Fluorophenyl column $(1.7 \mu \mathrm{m}, 50 \mathrm{~mm} \times 2.1 \mathrm{~mm})$ maintained at $30^{\circ} \mathrm{C}$. Compounds eluted through a steady stream $(0.35 \mathrm{~mL} / \mathrm{min})$ of binary mobile phase system that consisted of acetonitrile and water both infused with $0.1 \%$ formic acid. Composition of organic solvent were $5 \%$ at $0.00-0.50 \mathrm{~min}, 20 \%$ at $2.00 \mathrm{~min}, 50 \%$ at $4.00-5.50 \mathrm{~min}, 100 \%$ at $7.50-9.00 \mathrm{~min}$, and back again to $5 \%$ at $10.00-10.50 \mathrm{~min}$.

Mass spectrometry analysis in the positive ionization mode was carried out with the following tune settings: Capillary voltage of $3.20 \mathrm{~V}$, cone voltage of $45 \mathrm{~V}$, source offset of $80 \mathrm{~V}$, and source and desolvation temperature of $150^{\circ} \mathrm{C}$ and $500{ }^{\circ} \mathrm{C}$, respectively. Full-scan analysis was performed in the sensitivity mode of the instrument within $m / z$ 50-1500 range and scan time of $0.50 \mathrm{~s}$. Meanwhile, MS/MS analysis was accomplished using the DataDependent Acquisition (DDA) mode of the instrument. Selection of precursor ions were guided by a signal intensity threshold of $3.0 \times 10^{5}$ and sampling only the eight most abundant ions per scan. Fragmentation patterns were obtained through collision induced dissociation with argon curtain. To obtain comprehensive information for the different metabolites, profiling runs were executed under different collision energies $(15 \mathrm{eV}, 15-30 \mathrm{eV}$, $30-45 \mathrm{eV}$, and $45-60 \mathrm{eV}$ ). The same experimental method used to profile crude natural dye samples was used to analyze standard compounds.

\subsection{Bioinformatics Analysis}

DDA data in the form of Waters .RAW file were converted to open-source 32-bit .mzXML file format using the MSConvert tool of ProteoWizard MSConvert Version 3 Software [76]. Datasets on natural dyes were then uploaded and subjected to library search and molecular networking analysis in the cloud-based GNPS platform [21]. The library search workflow was used to provide putative identifications for the metabolites. Spectral hits that were displayed were limited to those with precursor and product ion deviation of less than $m / z 0.02$ and $m / z 0.05$, respectively. At least eight matched peaks also existed between sample and reference file, and the cosine (similarity) score exceeded $0.70[20,27]$. On the other hand, molecular networking generates consensus spectra for identical MS/MS scans that are within the same precursor ion and fragment ion mass tolerance. Precursor ions, represented as nodes, were then connected only if they would exceed six matched peaks and a cosine score of 0.70 . Maximum number of connections (topK) for each node were set at seven, and the maximum size of a single cluster was limited to 300 nodes [20,27]. After analysis in GNPS, the generated molecular networks were exported in the .graphml format to further customize network visualization on Cytoscape [77]. 


\subsection{UV-Vis Spectrophotometric Analysis}

Absorbance of extracted dyes of ultraviolet and visible radiation were investigated using a stand-alone Shimadzu Double Beam UV-Vis spectrophotometer. Colorant solutions were prepared in the concentration range of 32.5-250 ppm by way of serial dilution with water (Merck Lichrosolv, Kenilworth, NJ, USA). Samples were loaded in a one (1) cm quartz cuvette and the absorbance measurements were recorded in the $250-800 \mathrm{~nm}$ wavelength range.

Succeeding experiments explored the interaction of biowaste colorants with common dyeing mordants. Profiling of unmordanted extracts revealed that a solution concentration of $250 \mathrm{ppm}$ gave highly sensitive signals that do not exceed one absorbance unit. Mordanting with $\mathrm{FeSO}_{4}$, alum, and $\mathrm{CuSO}_{4}$ involved the mixing of $250 \mathrm{ppm}$ natural dye with varying concentrations $(10,50,125,250$, and $350 \mathrm{ppm})$ of mordant. The set-ups could react for $10 \mathrm{~min}$. After centrifugation, the supernatants were subjected to UV-Vis analysis.

\subsection{Textile Dyeing and Colorimetric Evaluation}

Dyeing experiments referred heavily on a reported method for natural dye application using cotton [65]. Total sizes of $4 \times 4 \mathrm{~cm}$ pieces of cotton fabric were pretreated by immersing in boiling solutions of mordants $\left(5 \mathrm{mg} / \mathrm{mL} \mathrm{FeSO}_{4}\right.$, alum, $\mathrm{CuSO}_{4}$, tartartic acid, and sodium carbonate) for $1 \mathrm{~h}$. After drying, fabrics were submerged in dye baths (1:10 liquor ratio), which consisted of $3 \mathrm{mg} / \mathrm{mL}$ extract and $3 \mathrm{mg} / \mathrm{mL}$ mordant. Dyeing was carried out for $1 \mathrm{~h}$ under a heating mantle that was kept at $100{ }^{\circ} \mathrm{C}$. The dyed pieces of cloth were then dried and washed three times with laboratory detergent. Colorimetric assessment of dyed fibers was carried out by taking scanned images of the dyeing panels and analyzing reflected color using the Digital Color Meter available on MacOS (Apple Inc., Cupertino, CA, USA).

\subsection{Multivariate Statistics}

XCMS Online [21] was used for the multivariate analysis of $\mathrm{MS}^{1}$ centroid data. Raw full scan data was converted to 64-bit .mzxml files via ProteoWizard MSConvert Version 3 Software [76]. Feature detection parameters include $5.0 \mathrm{ppm}$ for maximal tolerated $\mathrm{m} / \mathrm{z}$ deviation between consecutive scans, minimum and maximum peak widths of $2.0 \mathrm{~s}$ and $15.0 \mathrm{~s}$, respectively, signal-to-noise threshold of $1.0 \times 10^{2}$ prefilter intensity of $1.0 \times 10^{5}$, and noise filter of $1.0 \times 10^{3}$. These parameters were based on defaults suggested by XCMS for Waters high-resolution data [21] and were tweaked slightly to suit the samples for this study. Peak integration and normalization are built into the XCMS workflow. The Kruskal-Wallis non-parametric test was selected with $p$-value thresholds of significant and highly significant features set at 0.05 and 0.005 , respectively. Fold-change threshold for highly significant features is 1.5 and greater. Annotation parameters are $5.0 \mathrm{ppm}$ error and $0.015 \mathrm{ppm}$ for $\mathrm{m} / \mathrm{z}$ absolute error. A 100s width was considered for extracted ion chromatograms. PCA scores and loadings plots were log-transformed and centered and were replotted using OriginPro 8.5 (OriginLab Corporation, Northampton, MA, USA).

Supervised analysis was conducted using Metaboanalyst 5.0 [78] (https://www. metaboanalyst.ca, accessed on 15 August 2021). Converted Waters .RAW files were compressed and uploaded to the Metaboanalyst server with .txt metadata on color produced via $\mathrm{FeSO}_{4}$ complexation. centWave was chosen as a peak detection method, with $0.01 \mathrm{~m} / \mathrm{z}$ difference, 10.0 signal-to-noise threshold, 10.0 base width, $5.0 \mathrm{ppm}$ error tolerance, 5.0 and 30.0 minimum and maximum peak widths, and 1000.0 noise filter. While the peak detection algorithm of Metaboanalyst is the same with XCMS Online, some parameters from the latter are not compatible with Metaboanalyst. Consequently, parameters used in Metaboanalyst were optimized independently from XCMS Online.

Supplementary Materials: The following are available online, Figure S1: Dyebaths from the combination of biowaste colorants and mordant solutions, Figure S2: Tail-to-tail alignment of putatively identified metabolites from aqueous extract of T. catappa leaf, Figure S3: Tail-to-tail alignment of 
putatively identified metabolites from aqueous extract of D. philippinensis fruit peel, Figure S4: Tailto-tail alignment of putatively identified metabolites from aqueous extract of $S$. malaccense fruit peel, Figure S5: Tail-to-tail alignment of putatively identified metabolites from aqueous extract of S. samarangense fruit peel, Figure S6: Tail-to-tail alignment of putatively identified metabolites from aqueous extracts of E. deglupta bark and D. discolor fruit peel, Figure S7: Tandem MS/MS spectra for digallic acid and glucogallin, Figure S8: Proposed fragmentation scheme for sodiated ions of digallic acid and glucogallin, Figure S9: Tandem-MS spectrum for $\mathrm{m} / \mathrm{z} 603.0041$ associated with terminalin from Terminalia catappa leaf, Figure S10: Proposed fragmentation scheme for $m / z$ 603.0041 annotated as terminalin, Figure S11: Tandem-MS spectrum for $m / z 765.0583$ associated with terminalin-O-glucoside from Terminalia catappa leaf, Figure S12: Proposed fragmentation scheme for $m / z 765.0583$ annotated as terminalin-O-glucoside, Figure S13: Tandem-MS spectrum for $\mathrm{m} / \mathrm{z} 1067.0646$ associated with terminalin-O-glucoside-O-hexahydroxydiphenic acid from Terminalia catappa leaf, Figure S14: Proposed fragmentation scheme for $m / z 765.0583$ annotated as terminalinO-glucoside O-hexahydroxydiphenic acid, Figure S15: Tandem MS/MS spectra of $\mathrm{m} / \mathrm{z} 1171.2415$ annotated as (epi)catechin-(epi)catechin-(epi)catechin, Figure S16: Theoretical fragmentation of (Epi)catechin gallate-(Epi) catechin gallate-(Epi)catechin gallate, Figure S17: PCA scores plots of all dye extracts, Figure S18: Box-and-whisker plot corresponding to vitexin/isovitexin, Figure S19: Box-and-whisker plot corresponding to 2,4,6-trimethoxychalcone, Figure S20: Box-and-whisker plot corresponding to quercetin, Figure S21: Box-and-whisker plot corresponding to quercetin-Oarabinoside, Figure S22 Box-and-whisker plot corresponding to tiliroside, Figure S23: Box-andwhisker plot corresponding to dilinolein, Figure S24: Comparison of the UV-Vis spectra of T. catappa leaf and D. philippinensis fruit peel in the presence of $\mathrm{FeSO}_{4}$, alum, and $\mathrm{CuSO}_{4}$ mordant, Figure S25: Molecular networks of non-pigment metabolites from the extracted samples, Table S1: Colorimetric profile of the biowaste dyes measured in terms of Hue $\left(\mathrm{H}^{\circ}\right)$, Saturation $(\% \mathrm{~S})$, and Value $(\% \mathrm{~V})$, Table S2: List of putatively identified metabolites from aqueous dye from T. catappa leaf, Table S3: List of putatively identified metabolites from aqueous dye from $D$. philippinensis fruit peel, Table S4: List of putatively identified metabolites from aqueous dye from S. malacensse fruit peel, Table S5: List of putatively identified metabolites from aqueous dye from $S$. samarangense fruit peel, Table S6: List of putatively identified metabolites from aqueous dye from E. deglupta bark, Table S7: List of putatively identified metabolites from aqueous dye from $D$. blancoi fruit peel.

Author Contributions: Conceptualization: H.A.J.; Data Curation: R.J.E.J.M. and K.F.B.R.; Formal Analysis: R.J.E.J.M., K.F.B.R. and H.A.J.; Supervision: H.A.J. and R.B.N.; Writing-original draft: R.J.E.J.M. and K.F.B.R.; Writing-review and editing: R.J.E.J.M., K.F.B.R., R.B.N. and H.A.J. All authors have read and agreed to the published version of the manuscript.

Funding: This research was funded by the University of the Philippines Diliman Office of the Vice Chancellor for Research and Development (OVCRD) grant number 202016 ORG. The UPLC-QTOF mass spectrometer used for the analysis was procured through funding from the Department of Science and Technology-Philippine Council for Health Research and Development (DOST-PCHRD) under its Drug Discovery for Health Products program.

Institutional Review Board Statement: Not applicable.

Informed Consent Statement: Not applicable.

Data Availability Statement: The data presented in the study is detailed on the Supplementary Information. Additional information are available on request from the corresponding author.

Acknowledgments: The UP Diliman Mass Spectrometry Facility where the LC-MS experiments were carried out. The Analytical Service Laboratory for coordinating the use of the double beam UV-Vis spectrophotometer. The Jose Vera Santos Memorial Herbarium of the University of the Philippines Diliman-Institute of Biology for the taxonomic identification of the plant samples.

Conflicts of Interest: The authors declare no conflict of interest.

Sample Availability: Samples of the compounds are available from the authors. 


\section{References}

1. Adeel, S.; Amin, N.; Fazal-ur-Rehman; Ahmad, T.; Batool, F.; Hassan, A. Sustainable Isolation of Natural Dyes from Plant Wastes for Textiles. In Recycling from Waste in Fashion and Textiles; Pintu, P., Shakeel, A., Kunal, S., Sanjay, S., Eds.; John Wiley \& Sons, Ltd.: Hoboken, NJ, USA, 2020; pp. 363-390.

2. Khattab, T.A.; Abdelrahman, M.S.; Rehan, M. Textile Dyeing Industry: Environmental Impacts and Remediation. Environ. Sci. Pollut. Res. 2020, 27, 3803-3818. [CrossRef]

3. Mussak, R.A.M.; Bechtold, T. Natural Colorants in Textile Dyeing; John Wiley \& Sons, Ltd.: Hoboken, NJ, USA, 2009.

4. Lagashetti, A.C.; Dufossé, L.; Singh, S.K.; Singh, P.N. Fungal Pigments and Their Prospects in Different Industries. Microorganisms 2019, 7, 604. [CrossRef]

5. Adeel, S.; Rehman, F.; Pervaiz, M.; Hussaan, M.; Amin, N.; Majeed, A.; Rehman, H. Microwave Assisted Green Isolation of Laccaic Acid from Lac Insect (Kerria Lacca) for Wool Dyeing. Prog. Color. Color. Coat. 2021, 14, 293-299. [CrossRef]

6. Adeel, S.; Rafi, S.; Mustaan, M.A.; Salman, M.; Ghaffar, A. Animal Based Natural Dyes: A Short Review. In Handbook of Renewable Materials for Coloration and Finishing; Yusuf, M., Ed.; John Wiley \& Sons, Ltd.: Hoboken, NJ, USA, 2018; pp. 41-74. [CrossRef]

7. Mahdi, M.M.; Tuj-Zohra, F.; Ahmed, S. Dyeing of Shoe Upper Leather with Extracted Dye from Acacia Nilotica Plant Bark-An Eco-Friendly Initiative. Prog. Color. Color. Coat. 2020, 14, 241-258. [CrossRef]

8. Ribeiro, J.S.; Veloso, C.M. Microencapsulation of natural dyes with biopolymers for application in food: A review. Food Hydrocoll. 2021, 112, 106374. [CrossRef]

9. Patil, N.N.; Datar, A.G. Applications of natural dye from Ixora coccinea L. in the field of textiles and cosmetics. Color. Technol. 2016, 132, 98-103. [CrossRef]

10. Ahmad, N.A.; Yook-Heng, L.; Salam, F.; Mat Zaid, M.H.; Abu-Hanifah, S. A Colorimetric pH Sensor Based on Clitoria sp and Brassica sp for Monitoring of Food Spoilage Using Chromametry. Sensors 2019, 19, 4813. [CrossRef] [PubMed]

11. Richhariya, G.; Kumar, A.; Tekasakul, P.; Gupta, B. Natural dyes for dye sensitized solar cell: A review. Renew. Sust. Energ. Rev. 2017, 69, 705-718. [CrossRef]

12. Labrador, T.; Paz-Tauro, M.; Robis, E. Hibla Ng Lahing Filipino: The Artistry of Philippine Textiles; National Museum: Manila, Philippines, 2013; ISBN 9789715670210.

13. Habal, L.; de Guzman, Z. Gampol: A Compendium of Philippine Dye Yielding Plants and Their Textile Application; Philipphine Textile Research Institute, Department of Science and Technology (DOST): Makati City, Philippines, 2003; Volume 1, ISBN 9718551344.

14. Leaño, J.R. A Compendium of Philippine Dye-Yielding Plants and Their Extraction and Textile Application Technologies; Philipphine Textile Research Institute, Department of Science and Technology (DOST): Makati City, Philippines, 2008 ; Volume 2.

15. Davidson, J. Use of Principal Components, Factor Analysis and Varimax Rotation to Describe Variability in Wood of Eucalyptus Deglupta Blume. Wood Sci. Technol. 1975, 9, 275-291. [CrossRef]

16. Vankar, P.S. Natural Dyes for Textiles: Sources, Chemistry, and Applications, 1st ed.; Woodhead Publishing: Sawston, UK, 2017; ISBN 9780081018842. [CrossRef]

17. El-Zawahry, M.M.; El-Shami, S.; El-Mallah, M.H. Optimizing a Wool Dyeing Process with Reactive Dye by Liposome Microencapsulation. Dyes Pigm. 2007, 74, 684-691. [CrossRef]

18. Molino, R.J.E.J.; Junio, H.A. Profiling the Philippine Blue: Liquid Chromatography/Mass Spectrometry-Based Metabolomics Study on Philippine Indigofera. Rapid Commun. Mass Spectrom. 2021, 35, e9037. [CrossRef]

19. Zhou, B.; Xiao, J.F.; Tuli, L.; Ressom, H.W. LC-MS-Based Metabolomics. Mol. Biosyst. 2012, 8, 470-481. [CrossRef] [PubMed]

20. Wang, M.; Carver, J.J.; Phelan, V.V.; Sanchez, L.M.; Garg, N.; Peng, Y.; Nguyen, D.D.; Watrous, J.; Kapono, C.A.; Luzzatto-Knaan, T.; et al. Sharing and Community Curation of Mass Spectrometry Data with GNPS. Nat. Biotechnol. 2016, 34, 828-837. [CrossRef]

21. Tautenhahn, R.; Patti, G.J.; Rinehart, D.; Siuzdak, G. XCMS Online: A Web-Based Platform to Process Untargeted Metabolomic Data. Anal. Chem. 2012, 84, 5035-5039. [CrossRef]

22. Náthia-Neves, G.; Vardanega, R.; Meireles, M.A.A. Extraction of natural blue colorant from Genipa americana L. using green technologies: Techno-economic evaluation. Food Bioprod. Process. 2019, 114, 132-143. [CrossRef]

23. Veldkamp, J.F. Nomenclature of Syzygium gracile (Myrtaceae). Blumea 2003, 48, 489-490. [CrossRef]

24. Dacanay, F.; Ladra, M.; Junio, H.; Nellas, R. Molecular Affinity of Mabolo Extracts to an Octopamine Receptor of a Fruit Fly. Molecules 2017, 22, 1677. [CrossRef] [PubMed]

25. Loum, J.; Byamukama, R.; Wanyama, P.A.G. Efficient Extraction of Natural Dyes from Selected Plant Species. Chemistry Africa 2021, 4, 677-689. [CrossRef]

26. Ramos AE, F.; Evanno, L.; Poupon, E.; Champy, P.; Beniddir, M.A. Natural Products Targeting Strategies Involving Molecular Networking: Different Manners, One Goal. Nat. Prod. Rep. 2019, 36, 960-980. [CrossRef] [PubMed]

27. Nothias, L.F.; Nothias-Esposito, M.; da Silva, R.; Wang, M.; Protsyuk, I.; Zhang, Z.; Sarvepalli, A.; Leyssen, P.; Touboul, D.; Costa, J.; et al. Bioactivity-Based Molecular Networking for the Discovery of Drug Leads in Natural Product Bioassay-Guided Fractionation. J. Nat. Prod. 2018, 81, 758-767. [CrossRef]

28. Montoro, P.; Tuberoso, C.I.G.; Perrone, A.; Piacente, S.; Cabras, P.; Pizza, C. Characterisation by Liquid ChromatographyElectrospray Tandem Mass Spectrometry of Anthocyanins in Extracts of Myrtus Communis L. Berries Used for the Preparation of Myrtle Liqueur. J. Chromatogr. A 2006, 1112, 232-240. [CrossRef] [PubMed]

29. Cuyckens, F.; Claeys, M. Mass Spectrometry in the Structural Analysis of Flavonoids. J. Mass. Spectrom. 2004, 39, 1-15. [CrossRef] 
30. Kleinenkuhnen, N.; Büchel, F.; Gerlich, S.C.; Kopriva, S.; Metzger, S. A Novel Method for Identification and Quantification of Sulfated Flavonoids in Plants by Neutral Loss Scan Mass Spectrometry. Front. Plant Sci. 2019, 10, 885. [CrossRef]

31. Chang, Z.; Zhang, Q.; Liang, W.; Zhou, K.; Jian, P.; She, G.; Zhang, L. A Comprehensive Review of the Structure Elucidation of Tannins from Terminalia Linn. Evid. Based Complementary Altern. Med. 2019, 2019, 8623909. [CrossRef]

32. Zaccaron, S.; Ganzerla, R.; Bortoluzzi, M. Iron Complexes with Gallic Acid: A Computational Study on Coordination Compounds of Interest for the Preservation of Cultural Heritage. J. Coord. Chem. 2013, 66, 1709-1719. [CrossRef]

33. Waridel, P.; Wolfender, J.L.; Ndjoko, K.; Hobby, K.R.; Major, H.J.; Hostettmann, K. Evaluation of Quadrupole Time-of-Flight Tandem Mass Spectrometry and Ion-Trap Multiple-Stage Mass Spectrometry for the Differentiation of C-Glycosidic Flavonoid Isomers. J. Chromatogr. A 2001, 926, 29-41. [CrossRef]

34. Brazier-Hicks, M.; Evans, K.M.; Gershater, M.C.; Puschmann, H.; Steel, P.G.; Edwards, R. The C-Glycosylation of Flavonoids in Cereals. J. Biol. Chem. 2009, 284, 17926-17934. [CrossRef] [PubMed]

35. Oelrichs, P.B.; Pearce, C.M.; Zhu, J.; Filippich, L.J. Isolation and Structure Determination of Terminalin a Toxic Condensed Tannin from Terminalia Oblongata. Nat. Toxins 1994, 2, 144-150. [CrossRef] [PubMed]

36. Li, H.J.; Deinzer, M.L. Tandem Mass Spectrometry for Sequencing Proanthocyanidins. Anal. Chem. 2007, 79, 1739-1748. [CrossRef] [PubMed]

37. Singh, A.; Kumar, S.; Kumar, B. LC-MS Identification of Proanthocyanidins in Bark and Fruit of Six Terminalia Species. Nat. Prod. Commun. 2018, 13, 555-560. [CrossRef]

38. Jaiswal, R.; Jayasinghe, L.; Kuhnert, N. Identification and Characterization of Proanthocyanidins of 16 Members of the Rhododendron Genus (Ericaceae) by Tandem LC-MS. J. Mass. Spectrom. 2012, 47, 502-515. [CrossRef]

39. Matsubara, T.; Taniguchi, S.; Morimoto, S.; Yano, A.; Hara, A.; Wataoka, I.; Urakawa, H.; Yasunaga, H. Relationship between Dyeing Condition and Dyeability in Hair Colouring by Using Catechinone Prepared Enzymatically or Chemically from (+)Catechin. J. Cosmet. Dermatol. Sci. Appl. 2015, 5, 94-106. [CrossRef]

40. van den Berg, R.A.; Hoefsloot, H.C.J.; Westerhuis, J.A.; Smilde, A.K.; van der Werf, M.J. Centering, scaling, and transformations: Improving the biological information content of metabolomics data. BMC Genom 2006, 7, 142. [CrossRef]

41. Ghouila, H.; Meksi, N.; Haddar, W.; Mhenni, M.F.; Jannet, H.B. Extraction, Identification and Dyeing Studies of Isosalipurposide, a Natural Chalcone Dye from Acacia Cyanophylla Flowers on Wool. Ind. Crop. Prod. 2012, 35, 31-36. [CrossRef]

42. Formica, J.V.; Regelson, W. Review of the biology of quercetin and related bioflavonoids. Food Chem. Toxicol. 1995, 33, 1061-1080. [CrossRef]

43. Gürses, A.; Açıkyıldız, M.; Güneş, K.; Gürses, M.S. Dyes and Pigments: Their Structure and Properties. In Dyes and Pigments; Springer International Publishing: Cham, Switzerland, 2016; pp. 13-29.

44. Ge, X.; Timrov, I.; Binnie, S.; Biancardi, A.; Calzolari, A.; Baroni, S. Accurate and Inexpensive Prediction of the Color Optical Properties of Anthocyanins in Solution. J. Phys. Chem. A. 2015, 119, 3816-3822. [CrossRef]

45. Bancirova, M. Changes of the Quercetin Absorption Spectra in Dependence on Solvent. Chemistry 2015, 1, 31-34.

46. Park, H.R.; Daun, Y.; Park, J.K.; Bark, K.M. Spectroscopic Properties of Flavonoids in Various Aqueous-Organic Solvent Mixtures. Bull. Korean Chem. Soc. 2013, 34, 211-220. [CrossRef]

47. Cysewski, P.; Jeliński, T.; Przybyłek, M.; Shyichuk, A. Color Prediction from First Principle Quantum Chemistry Computations: A Case of Alizarin Dissolved in Methanol. New J. Chem. 2012, 36, 1836-1843. [CrossRef]

48. Malcioğlu, O.B.; Calzolari, A.; Gebauer, R.; Varsano, D.; Baroni, S. Dielectric and Thermal Effects on the Optical Properties of Natural Dyes: A Case Study on Solvated Cyanin. J. Am. Chem. Soc. 2011, 133, 15425-15433. [CrossRef]

49. Roy, S.; Rhim, J.-W. Anthocyanin Food Colorant and Its Application in PH-Responsive Color Change Indicator Films Change Indicator Films. Crit Rev. Food. 2020, 61, 2297-2325. [CrossRef]

50. Burgos, G.; Amoros, W.; Muñoa, L.; Sosa, P.; Cayhualla, E.; Sanchez, C.; Díaz, C.; Bonierbale, M. Total Phenolic, Total Anthocyanin and Phenolic Acid Concentrations and Antioxidant Activity of Purple-Fleshed Potatoes as Affected by Boiling. J. Food Compos. Anal. 2013, 30, 6-12. [CrossRef]

51. Briggs, T.R. The Physical Chemistry of Dyeing: Substantive Dyes. J. Phys. Chem. 1932, 28, 368-386. [CrossRef]

52. Phan, K.; van den Broeck, E.; van Speybroeck, V.; de Clerck, K.; Raes, K.; de Meester, S. The Potential of Anthocyanins from Blueberries as a Natural Dye for Cotton: A Combined Experimental and Theoretical Study. Dye. Pigm. 2020, 176, 108180. [CrossRef]

53. Sigurdson, G.T.; Giusti, M.M. Bathochromic and Hyperchromic Effects of Aluminum Salt Complexation by Anthocyanins from Edible Sources for Blue Color Development. J. Agric. Food Chem. 2014, 62, 6955-6965. [CrossRef] [PubMed]

54. Mabry, T.; Markham, K.R.; Thomas, M.B. The Systematic Identification of Flavonoids; Springer: New York, NY, USA, 1970.

55. Zheng, Y.Z.; Zhou, Y.; Liang, Q.; Chen, D.F.; Guo, R. Theoretical Studies on the Hydrogen-Bonding Interactions between Luteolin and Water: A DFT Approach. J. Mol. Model. 2016, 22, 257. [CrossRef]

56. Amat, A.; Clementi, C.; Miliani, C.; Romani, A.; Sgamellotti, A.; Fantacci, S. Complexation of Apigenin and Luteolin in Weld Lake: A DFT/TDDFT Investigation. Phys. Chem. Chem. Phys. 2010, 12, 6672-6684. [CrossRef]

57. Smith, G.J.; Thomsen, S.J.; Markham, K.R.; Andary, C.; Cardon, D. The Photostabilities of Naturally Occurring 5-Hydroxyflavones, Flavonols, Their Glycosides and Their Aluminium Complexes. J. Photochem. Photobiol. A 2000, 136, 87-91. [CrossRef]

58. Pẹkal, A.; Biesaga, M.; Pyrzynska, K. Interaction of Quercetin with Copper Ions: Complexation, Oxidation and Reactivity towards Radicals. BioMetals 2011, 24, 41-49. [CrossRef] 
59. Mira, L.; Fernandez, M.T.; Santos, M.; Rocha, R.; Florêncio, M.H.; Jennings, K.R. Interactions of Flavonoids with Iron and Copper Ions: A Mechanism for Their Antioxidant Activity. Free Radic. Res. 2002, 36, 1199-1208. [CrossRef]

60. Lekka, C.E.; Ren, J.; Meng, S.; Kaxiras, E. Structural, Electronic, and Optical Properties of Representative Cu-Flavonoid Complexes. J. Phys. Chem. 2009, 113, 6478-6483. [CrossRef] [PubMed]

61. Fernandez, M.T.; Mira, M.L.; Florêncio, M.H.; Jennings, K.R. Iron and Copper Chelation by Flavonoids: An Electrospray Mass Spectrometry Study. J. Inorg. Biochem. 2002, 92, 105-111. [CrossRef]

62. Leopoldini, M.; Russo, N.; Chiodo, S.; Toscano, M. Iron Chelation by the Powerful Antioxidant Flavonoid Quercetin. J. Agric. Food Chem. 2006, 54, 6343-6351. [CrossRef]

63. Jeevitha, D.; Sadasivam, K.; Praveena, R.; Jayaprakasam, R. DFT Study of Glycosyl Group Reactivity in Quercetin Derivatives. J. Mol. Struct. 2016, 1120, 15-24. [CrossRef]

64. Matsubara, T.; Wataoka, I.; Urakawa, H.; Yasunaga, H. Effect of Reaction PH and CuSO4 Addition on the Formation of Catechinone Due to Oxidation of (+)-Catechin. Int. J. Cosmet. Sci. 2013, 35, 362-367. [CrossRef]

65. Mongkholrattanasit, R.; Klaichoi, C.; Rungruangkitkrai, N.; Punrattanasin, N.; Sriharuksa, K.; Nakpathom, M. Dyeing Studies with Eucalyptus, Quercetin, Rutin, and Tannin: A Research on Effect of Ferrous Sulfate Mordant. J. Text. 2013, 2013 , 423842. [CrossRef]

66. Elhabiri, M.; Carrër, C.; Marmolle, F.; Traboulsi, H. Complexation of Iron(III) by Catecholate-Type Polyphenols. Inorganica Chim. Acta 2007, 360, 353-359. [CrossRef]

67. Jolliffe, I.T. Principal Component Analysis, 1st ed.; Springer: New York, NY, USA, 1986.

68. Worley, B.; Powers, R. PCA as a practical indicator of OPLS-DA model reliability. Curr. Metab. 2016, 4, 97-103. [CrossRef]

69. Barani, H.; Montazer, M. A Review on Applications of Liposomes in Textile Processing. J. Liposome Res. 2008, 18, 249-262. [CrossRef] [PubMed]

70. Montazer, M.; Taghavi, F.A.; Toliyat, T.; Moghadam, M.B. Optimization of dyeing of wool with madder and liposomes by central composite design. J. Appl. Polym. Sci. 2007, 106, 1614-1621. [CrossRef]

71. Martí, M.; Coderch, L.; de la Maza, A.; Parra, J.L. Liposomes of phosphatidylcholine: A biological natural surfactant as a dispersing agent. Color. Technol. 2007, 123, 237-241. [CrossRef]

72. Villela, A.; van Vuuren, M.S.A.; Willemen, H.M.; Derksen, G.C.H.; van Beek, T.A. Photo-stability of a flavonoid dye in presence of aluminium ions. Dye. Pigm 2019, 162, 222-231. [CrossRef]

73. Manian, A.P.; Paul, R.; Bechtold, T. Metal mordanting in dyeing with natural colourants. Color. Technol. 2016, 132, 107-113. [CrossRef]

74. İşmal, Ö.E.; Yıldırım, L. Metal Mordants \& Biomordants. In The Impact and Prospects of Green Chemistry for Textile Technology, 1st ed.; ul Islam, S., Butola, B.S., Eds.; Woodhead Publishing: Sawston, UK, 2019; pp. 57-82.

75. Oda, H. Improvement of light fastness of natural dyes. Part 2: Effect of functionl phenyl esters on the photofading of carthaminin polymeric substrate. Color. Technol. 2001, 117, 257-261. [CrossRef]

76. Chambers, M.C.; Maclean, B.; Burke, R.; Amodei, D.; Ruderman, D.L.; Neumann, S.; Gatto, L.; Fischer, B.; Pratt, B.; Egertson, J.; et al. A cross-platform toolkit for mass spectrometry and proteomics. Nat. Biotechnol. 2012, 30, 918-920. [CrossRef]

77. Shannon, P.; Markiel, A.; Ozier, O.; Baliga, N.; Wang, J.; Ramage, D.; Amin, N.; Schwikowski, B.; Ideker, T. Cytoscape: A Sofwatre Environment for Integrated Models. Genome Res. 1971, 13, 426. [CrossRef]

78. Pang, Z.; Chong, J.; Zhou, G.; de Lima Morais, D.A.; Chang, L.; Barrette, M.; Gauthier, C.; Jacques, P.; Li, S.; Xia, J. Metaboanalyst 5.0: Narrowing the Gap between Raw Spectra and Functional Insights. Nucleic Acids Res. 2021, 49, 388-396. [CrossRef] 